\title{
Understanding the COVID-19 Pandemic Awareness among Indian Population- An Analysis of Online Rapid Survey
}

\author{
Rajat Garg*, Anita Bhargava**, Namita Sharma**** \\ "Immunization, JSI India \\ ** Immunization, JSI India \\ *** Opthamology, Jawaharlal Rohtagi Eye Hospital \\ DOI: 10.29322/IJSRP.10.07.2020.p10348 \\ http://dx.doi.org/10.29322/IJSRP.10.07.2020.p10348
}

\begin{abstract}
The COVID-19 outbreak has been rapid worldwide so as the spread of the disease among population at different age cohorts. Hence it required quick and clear awareness among population to minimize the morbidity and mortality perpetuated by the virus, about which the world has speculative information. The aim of the present study is to bring out the results of the knowledge and perception regarding Corona virus disease 2019 (COVID-19) among general public of India. An online rapid survey through google form was carried out from 24 March to 26 March, 2020 carrying a set of 10 questions. Uni-variate analyses and graphical representation of the findings were performed to present the distribution of the parameters. More than $60 \%$ of the respondents have misconceptions about COVID-19. Out of all, the respondents have wide misconceptions about transmission of the disease from pets such as dogs or cats. There is a continuous need of educational interventions to spread awareness and minimize the misconceptions and myths of general population.
\end{abstract}

Index Terms- Morbidity, Mortality, COVID-19, Awareness, Misconception

\section{INTRODUCTION}

Globally, there are more than 83 lakhs confirmed cases and 4 lakhs deaths due to the novel Corona virus (COVID-19) disease caused by SARS CoV-2.[1] The number of cases and the death toll are continuing to rise. Nevertheless, the recovered cases from the disease has started illuminating a ray of hope and humanity may come over the pandemic in coming times.

In the month of March when the disease was declared as global pandemic by WHO, as by then 114 countries had already been affected [2], the total number cases in India were less than 100 which surged up to more than one lakh confirmed cases just within the two months at the time of writing the present study.

Dry cough, fever, fatigue, headache, myalgia and dyspnoea are some of the symptoms of the invisible deadly disease.[3] As the country is swinging in transition of winning the widespread pandemic, the government health care authorities in India took unprecedented measures hurriedly in order to curtail the spread of the virus among its vast population, primarily through lockdown leading to social distancing and reduction in social gatherings. Apart from, all kinds of platforms were used to disseminate the awareness and knowledge among the population irrespective of educational and socio-economic disparities. It is believed that the success largely depends upon people's adherence to the control measures which is largely influenced by their knowledge, attitudes and practices towards the global pandemic.[3] However, it is also a fact that the misconceptions and myths linger around the general public.[4] Therefore, the present study is an attempt to understand the knowledge and perceptions about COVID-19 among the general public in India.

\section{METHODS}

An on-line survey was carried out among the adult population of India and their participation was completely voluntary. Rapid online surveys are an important tool to gather data on population's knowledge and perceptions during rapidly growing infectious disease outbreaks [5], currently the use of paper and telephone surveys are being replaced by the application of online surveys.[6] In current times, internet and social networking are indispensable modes which render information quickly so that it reaches everywhere in a minimal time. In the present study as well, the use of online survey not only helped to obtain quick data related to misconceptions and understanding of population related to COVID-19 pandemic but it also illuminated a path to where educational interventions can be made prompter and more persuasive.

With the help of convenience sampling method, the questionnaire was floated to the social medial- WhatsApp, Facebook and Google accounts. The self-administered questionnaire consisted of 10 questions based on the knowledge, awareness and practices related to the COVID-19 pandemic that developed after interim guidance and information spread through government health care authorities as well as private forums. The questionnaires reflected the myths and misconceptions related to Coronavirus spread. The collected data 
was tabulated in excel and descriptive statistics were performed. The distribution of responses is presented with frequency and percentages.

\section{FINDINGS}

A total of 247 respondents across the country responded to the survey. Figure 1 represents the total scores of the questions. The total score has been computed as the summation of the correct point of each question. For example, if a respondent has given correct answers to all 10 questions, then the total score is 10 . Likewise, if a respondent could answer only 4 questions correctly, then the total score is 4. The mean of the total score is 8.8 . About 39 per cent of the respondents gave correct answers to all questions showing that 61 percent of the population has one or more misconceptions. Almost one-third of the respondents had more than two misconceptions. These respondents are grappled with misconceptions which is needed to be mitigated at a large scale.

Figure 2 showed the percentage of question-wise correct answers given by the respondents. Out of 10, correct response to four questions is more than 90 percent while other five questions received the correct response between 80-90 per cent.

99.6 per cent $(n=246)$ of the total respondents given correct answer that cold weather and snow cannot kill Coronavirus. As the history of the spread is seen, the first Coronavirus patient was detected in Wuhan city of China during the months of September when winter season was gradually starting and the number of cases continued to rise globally particularly affecting higher latitude countries such as USA, Italy, U.K, Russia and so on. Even in the month of May when the average temperature in India is recorded as $40-42^{\circ} \mathrm{C}$, the number of cases in India as well as worldwide is on rise. [2]

96.8 per cent $(n=239)$ of the respondents clearly knew the transmission sources of Coronavirus and hence, responded that mosquito bites do not spread the infection. Likewise, 92.3 per cent $(n=241)$ of the total respondents responded that the vaccine against Pneumonia such as Pneumococcal vaccine and Haemophilus Infleunzae type b (Hib) vaccine would not provide protection against Coronavirus. This is quite well understood by the population that there's no successful vaccine available till date for the disease. Similar to the question, around 90.7 per cent $(n=224)$ of the respondents reported that no medicine till date is recommended to cure the disease completely and hence precautions and preventive measures are the only ways to mitigate it.

88.7 per cent $(n=219)$ of the volunteers accepted that regularly rinsing of nasal passage with saline water did not protect people from getting infected with the virus. Practicing yoga is one of the messages which had been spread during the lockdown period in the country. As acclaimed, yoga is one of the greatest tools to increase respiratory health and immunity, both are involved in the prevention and healing of COVID-19. The practice of rinsing nasal passage has been documented in Yoga related various studies as well as highlighted on United Nations' webpage. [6,7]. However, there has not been any scientific-evidence of direct relationship. [7], [8]

The healthcare authorities also encouraged the intake of healthy foods such as green leafy vegetables, cut down in junk foods, intake of plenty of water, citrus fruits enriched with Vitamin C and so on. There had been a prevalent myth that inclusion of garlic in the food would reduce the risk of getting infected with the Coronavirus. 84.6 per cent $(n=209)$ volunteers responded that garlic cannot protect population from getting infected. WHO has also inculcated awareness among population by displaying myth busters where they advise that garlic has some antimicrobial properties but there is no scientific evidence that it would provide sufficient protection against the pandemic.[9]

\section{DISCUSSION}

Ever since the outbreak of COVID-19 pandemic in China, it has a cascaded effect worldwide [10] leaving behind surged fatal cases and India is one of among such badly affected countries. Like any other developing nations, the pandemic is a serious concern in India because of larger share of senile population, lack of sufficient health infrastructural facilities, exodus movements of migrant labours from their cities of work place to their hometowns, educational and socio-economic disparities and other proximate factors. As on date, India has more than 3.8 lakhs confirmed cases and 12573 reported deaths due to COVID-19. India has become $4^{\text {th }}$ worst affected countries of Coronavirus pandemic [11] and it will continue to grow, as forecasted by many scholars for instance, the peak of COVID_19 pandemic in India may arrive around mid-November, 2020 when there will be shortage of isolation, ICU beds and ventilators. [12]

In order to remain safe from the infection, it is important to practice safe measures and refrain from misconceptions and myths. Further, large amount of information has been floating on all kinds of social media platforms out of which many are "false information and news" against which the population should remain cautious. The commendable action plans by the health care authorities in India are extremely helpful in delivering correct information to the public but offshoots continue to make the population believe in misconceptions. With an average of 87.7 per cent with 99.6 as the highest percentage of correct response and 70.4 as the lowest response, the awareness among volunteers seemed to be considerable; however, misconceptions are yet to be minimised through educational interventions. Correct information, safe hygienic practices and healthier lifestyle would lead the population to safeguard them against the pandemic. However, myths and misconceptions continue to sustain in relation to pets and Coronavirus spread. As 70 per cent of the volunteers believed that it cannot be transferred through the pets, about 30 per cent of them think otherwise. Further, recent studies have shown that the pets can get affected with the virus however, how much they could spread the disease is still unsure as no concrete studies have come up till now.[13]-[15] A report published in Times of India mentioned that person who are 
symptomatic with SARS-CoV-2 should remain separated from household animals and avoid direct contact such a petting, snuggling, cuddling, sleeping in the same locations and alike behavior. [13]

This study is first of its kind where general population's awareness on COVID-19 has been assessed to the best of our knowledge. Since the initial days when the disease was declared as pandemic, actions by the government had been rendered and changing accordingly with time and spreading behavior of the virus. Such steps are supportive for the society to reduce their levels of worry and anxiety and utmost of all, significant in saving lives.

\section{CONCLUSION}

As India is yet to reach at the flatten curve of SARS CoV-2 pandemic, current situations urge proactive actions and mitigation of the misconceptions and myths prevalent among the general population. Since, effective vaccine preparation is under trial currently, for instance, clinical trials with hydroxychloroquine are underway and results are awaited as the effectiveness will be monitored closely in near future[16], preventive and precautious measures are believed to be extremely helpful. We consider that the results of this study can be of great utility for the health authorities, medical personnel, the media and the general population, to know the perception of general population about COVID-19. The findings can be utilized to set priorities in Mass campaigns on COVID-19 by authorities.

\section{LIMITATION OF THE STUDY}

As the study was carried in a very short span of time and with a limited number of questions asked to the volunteers, it has several limitations which gives an opportunity to be explored further.

1. The period was very short and hence the sample size was small.

2. Convenience sampling is not a true representative of general population.

3. There is a volunteer bias in the study hence not representative of general population

4. Participants could have checked the answers of some questions online before answering

\section{APPENDIX}

\section{Online Rapid Survey: The COVID-19 Myth Challenge among Public}

Question-1: Cold weather and snow can kill the Corona Virus.
A. Yes
B. No (Correct Answer)

Question-2: The Corona Virus cannot be transmitted in areas with hot and humid climates.
A. Yes
B. No (Correct Answer)

Question-3: The Corona Virus CAN be transmitted through mosquito bites.
A. Yes
B. No (Correct Answer)

Question-4: There is NO evidence that companion animals/pets such as dogs or cats can transmit the Corona Virus.
A. Yes
B. No (Correct Answer)

Question-5: Taking a hot bath prevents the Coronavirus.
A. Yes
B. No (Correct Answer)

Question-6: Thermal scanners CAN detect whether or not someone has the Corona Virus.
A. Yes
B. No (Correct Answer)

Question-7: Vaccines against pneumonia, such as pneumococcal vaccine and Haemophilus influenzae type b (Hib) vaccine provide protection against the Coronavirus.
A. Yes
B. No (Correct Answer)

Question-8: There is evidence that regularly rinsing the nose with saline has protected people from infection with the Coronavirus.
A. Yes
B. No (Correct Answer)

Question-9: Garlic is healthy and there is evidence from the current outbreak that eating garlic has protected people from the Corona Virus. 

A. Yes
B. No (Correct Answer)

Question-10: To date, there is NO specific medicine recommended to prevent or treat the Coronavirus.

A. True (Correct Answer)

B. False

\section{ACKNOWLEDGMENT}

Authors are thankful to Dr Lokesh Alahari (public health expert) who supported in designing the questionnaire

\section{REFERENCES}

[1] WHO, "Coronavirus disease (COVID-19)," 2020.

[2] WHO, "Coronavirus (COVID-19) events as they happen," https://www.who.int/emergencies/diseases/novelcoronavirus-2019/events-as-they-happen, [Online]. $2020 . \quad$ Available: https://www.who.int/emergencies/diseases/novel-coronavirus-2019/events-as-they-happen. [Accessed: 24-May2020].

[3] B. L. Zhong et al., "Knowledge, attitudes, and practices towards COVID-19 among Chinese residents during the rapid rise period of the COVID-19 outbreak: a quick online cross-sectional survey," Int. J. Biol. Sci., vol. 16, no. 10, pp. 1745-1752, 2020.

[4] K. Ajilore, I. Atakiti, and K. Onyenankeya, "College students' knowledge, attitudes and adherence to public service announcements on Ebola in Nigeria: Suggestions for improving future Ebola prevention education programmes," Health Educ. J., vol. 76, no. 6, pp. 648-660, 2017.

[5] P. Geldsetzer, "Use of rapid online surveys to assess people's perceptions during infectious disease outbreaks: A Crosssectional Survey on COVID-19," J. Med. Internet Res., vol. 22, no. 4, pp. 1-13, 2020.

[6] "From Telephone to the Web: The Challenge of Mode of Interview Effects in Public Opinion Polls - Pew Research Center Methods | Pew Research Center." [Online]. Available: https://www.pewresearch.org/methods/2015/05/13/from-telephone-to-the-web-the-challenge-of-mode-of-intervieweffects-in-public-opinion-polls/. [Accessed: 24-May-2020].

[7] “COVID-19 Yoga Tips — Yoga Bharati." [Online]. Available: https://yogabharati.org/covid19-yoga-tips. [Accessed: 25-May-2020].

[8] G. Tillu, S. Chaturvedi, A. Chopra, and B. Patwardhan, "Public Health Approach of Ayurveda and Yoga for COVID19 Prophylaxis," J. Altern. Complement. Med., vol. 26, no. 5, pp. 360-364, 2020.

[9] "Myth busters." [Online]. Available: https://www.who.int/emergencies/diseases/novel-coronavirus-2019/advice-forpublic/mythbusters?gclid=CjwKCAjw2a32BRBXEiwAUcugiHz9Uf7km7OMMVauzVoQDOzZNC_qMedFujhTSS0QZEH2X jX-YvJyxoCM_QQAvD_BwE\#garlic. [Accessed: 25-May-2020].

[10] P. D. Modi et al., "COVID-19 Awareness Among Healthcare Students and Professionals in Mumbai Metropolitan Region: A Questionnaire-Based Survey," Cureus, Apr. 2020.

[11] "Coronavirus update: COVID-19 cases in India reach 1.38 lakh, nearly 7,000 new cases in last 24 hours." [Online]. Available: https://www.livemint.com/news/india/coronavirus-update-covid-19-cases-in-india-reach-1-38-lakhnearly-7-000-new-cases-in-last-24-hours-11590376470773.html. [Accessed: 25-May-2020].

[12] S. Niazi, "Coronavirus in India may peak in mid-Nov, study says," Coronavirus in India may peak in mid-Nov, study says, 2020. [Online]. Available: https://www.aa.com.tr/en/asia-pacific/coronavirus-in-india-may-peak-in-mid-novstudy-says/1876893. [Accessed: 27-Jun-2020].

[13] "Pets can get Covid-19 from humans: Study | Delhi News - Times of India." [Online]. Available: https://timesofindia.indiatimes.com/city/delhi/pets-can-get-covid-19-from-humans-study/articleshow/75767405.cms. [Accessed: 25-May-2020].

[14] "COVID-19 and Animals | CDC." [Online]. Available: https://www.cdc.gov/coronavirus/2019-ncov/daily-lifecoping/animals.html. [Accessed: 25-May-2020].

[15] "Q\&A on coronaviruses (COVID-19)." [Online]. Available: https://www.who.int/emergencies/diseases/novelcoronavirus-2019/question-and-answers-hub/q-a-detail/q-a-coronaviruses. [Accessed: 25-May-2020].

[16] O. Mitjà and B. Clotet, "Use of antiviral drugs to reduce COVID-19 transmission," Lancet Glob. Heal., vol. 8, no. 5, pp. e639-e640, 2020. 


\section{AUTHORS}

First Author- Rajat Garg, MBBS, JSI India, New Delhi, India, rajatgarg123@gmail.com Second Author- Anita Bhargava, PhD, JSI India, New Delhi, India annubps@gmail.com

Third Author- Namita Sharma, MBBS, Jawaharlal Rohtagi Eye Hospital, Kanpur Nagar, Uttar Pradesh, India, namitasharmajnmc@gmail.com

Correspondence Author- Rajat Garg, MBBS, JSI India, New Delhi, India, rajatgarg123@ gmail.com

Figure 1: Distribution of Total Scores of the Questions

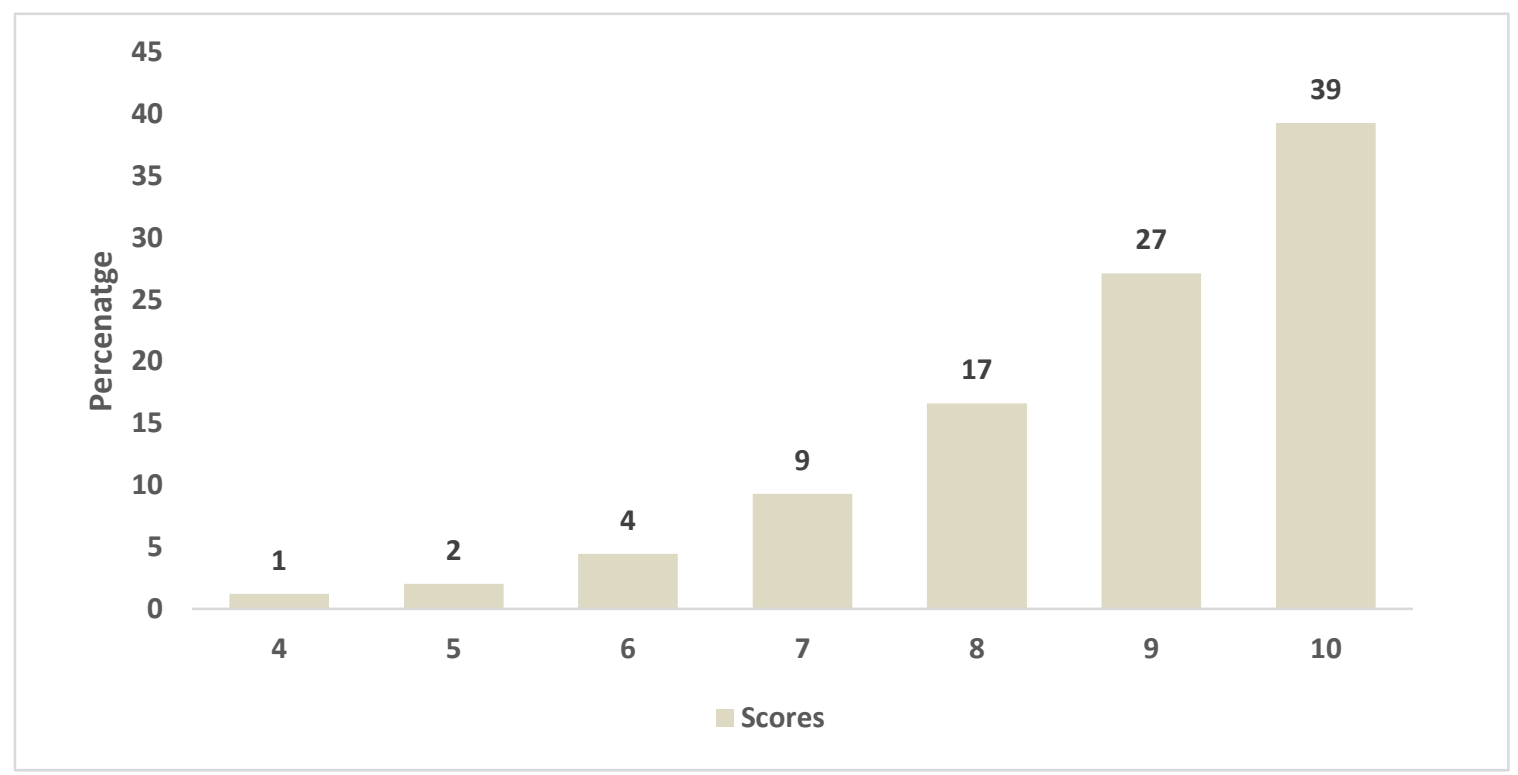

Figure 2: Distribution of Correct Answers by the respondents

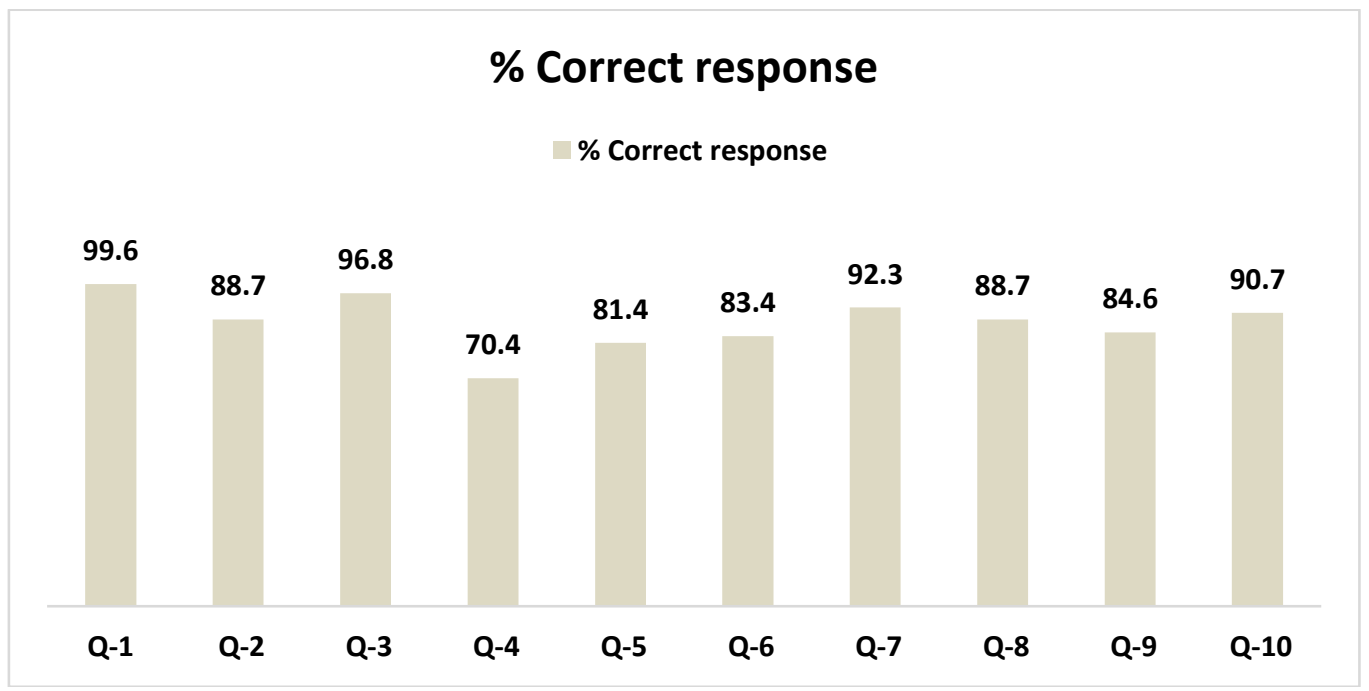

